\title{
Análise de Modelos de Mesoescala para Caracterização do Potencial Eólico do Estado da Paraíba
}

\author{
Soetânia Santos de Oliveira ${ }^{1}$, Enio Pereira de Souza ${ }^{1}$ \\ ${ }^{1}$ Departamento de Ciências Atmosféricas, Universidade Federal de Campina Grande, \\ Campina Grande, PB, Brasil.
}

Recebido em 17 de Junho de 2016 - Aceito em 9 de Fevereiro de 2017

\begin{abstract}
Resumo
O objetivo deste estudo foi avaliar o desempenho de modelos numéricos de mesoescala em simular condições de vento no estado da Paraíba-BRA. Para isso um estudo de caso foi realizado para o mês de setembro de 2010, no qual foram comparados dados de velocidade do vento coletados a partir de sensores instalados em torres anemométricas padronizadas para estudos eólicos com dados simulados pelos modelos BRAMS e WRF. As torres estão localizadas nas mesorregiões do Agreste, Borborema e Sertão da Paraíba-BRA. Os resultados revelam que para a localidade analisada no Agreste o WRF acompanha as variações de velocidade média do vento de forma mais concisa, ao passo que para as localidades situadas na Borborema e no Sertão os ciclos reproduzidos pelo BRAMS mostraram-se mais próximos dos ciclos observados. De acordo com a análise estatística os maiores erros foram encontrados para a localidade da Borborema e os menores para a do Agreste, ambos para os resultados do WRF. De modo geral, os dados observados e simulados pelos modelos apresentam uma forte correlação com significância estatística de $99 \%$ de acordo com o teste estatístico aplicado.
\end{abstract}

Palavras-chave: potencial eólico, simulação numérica, modelos de mesoescala.

\section{Mesoescale Models Analysis to Characterize of the Wind Power over Paraíba State}

\begin{abstract}
The objective of this study was to evaluate the performance of mesoescale numerical models to simulate wind conditions in the state of Paraiba-BRA. For this a case study was conducted for the month of September 2010, which compared data of wind speed collected from sensors installed on towers anemometric standard for wind studies with simulated data by BRAMS and WRF models. The towers are located in the regions of Agreste, Borborema and Sertão from the Paraíba-BRA. The results reveal that for the locality analyzed in Agreste the WRF accompanying variations in average wind speed more concisely, while for the locations situated in the Borborema and Sertão cycles played by BRAMS showed up closer to the observed cycles. According to the greatest statistical errors were found for the location in Borborema and lower for the wild both to the results of the WRF. In general, the observed and simulated by the models show a strong correlation with statistical significance of $99 \%$ according to the statistical test.
\end{abstract}

Keywords: wind power, numerical simulation, mesoescale models.

\section{Introdução}

A maior parte da energia elétrica utilizada no Brasil vem de recursos hídricos. Em termos de segurança energética, é importante buscar alternativas que possibilitem diminuir a alta dependência das hidrelétricas, tendo em vista a vulnerabilidade destas às condições climáticas (Silva et al., 2005). Dentre as fontes renováveis a energia eólica é uma que vem se destacando ao longo dos tempos. De acordo com o Plano Decenal de Expansão de Energia - PDE 2021, a geração eólica é a fonte que mais cresceu no Brasil em participação nos leilões desde 2009 (MME/EPE, 2012).

A definição do potencial eólico de uma região tem na velocidade média do vento local um elemento central, uma vez que a potência eólica disponível é diretamente propor-

Autor de correspondência: Soetânia Santos de Oliveira, soetania@gmail.com. 
cional ao cubo da velocidade do vento (Santos et al., 2015; Sansigolo, et al., 2005). Portanto, pequenos erros na estimativa da velocidade podem acarretar alterações muito significativas no potencial do local. Isto evidencia a necessidade de uma análise prévia do lugar onde se pretende construir um parque eólico, bem como na definição da viabilidade técnica e econômica do empreendimento, para que se tenha um aproveitamento melhor da potencialidade da energia eólica (Silva et al., 2003).

Desde a última década vários métodos vêm sendo utilizados para avaliação do potencial eólico. O interesse em aplicações da modelagem numérica da atmosfera para esse fim é crescente e já movimenta um mercado significativo, uma vez que o uso de modelos numéricos pode auxiliar tanto na identificação de localidades com elevado potencial eólico quanto, serem usados operacionalmente na previsão de geração de energia em curto prazo.

A habilidade dos modelos para avaliação dos recursos eólicos tem sido foco de vários estudos como, por exemplo, Lazic et al. (2010) que avaliaram o desempenho do modelo Eta para previsões de velocidade do vento e encontraram resultados que indicam que o modelo Eta pode ser usado como um guia meteorológico para a modelagem e previsão de energia eólica.

Wang et al. (2011) realizaram uma análise comparativa dos principais modelos de previsão associados a velocidade do vento e energia e concluíram que não existe um modelo único que seja melhor em todos os casos e que a precisão da previsão piora em terreno complexo e com o passar do tempo.

Lima et al. (2012), buscando descrever a densidade de potência eólica e avaliar a capacidade do modelo BRAMS - Brazilian Developments on the Regional Atmospheric Modelling System, em descrever a intensidade do vento em cinco localidades da Paraíba, verificaram que o modelo é capaz de reproduzir satisfatoriamente os ciclos mensais do vento e a direção predominante com alta correlação entre os dados simulados e observados.

Ramos et al. (2013), utilizaram o modelo atmosférico WRF para realizar um prognóstico do vento para o Estado de Alagoas, e verificaram que as previsões do vento do modelo WRF - Weather Research and Forecasting System, pode ser usadas como um instrumento computacional eficaz e importante na realização de levantamentos deste tipo, pois sua acurácia na determinação dos padrões médios da velocidade e direção do vento, além do seu desempenho na identificação de fenômenos locais reforça a tese de sua qualidade nos prognósticos de mesoescala.

O objetivo deste estudo foi avaliar o desempenho de modelos numéricos de mesoescala em simular condições de vento no estado da Paraíba-BRA. Para isso os modelos BRAMS e WRF foram utilizados para gerar cenários de condições de vento e assim analisar os ciclos mensal e diário. Além disso, foram realizadas análises estatísticas que permitiram avaliar o desempenho dos modelos para cada localidade e altura analisada.

\section{Metodologia}

\section{1. Área de estudo}

A área de estudo é o estado da Paraíba, que está situada no extremo leste da região Nordeste do Brasil (NEB), entre os paralelos $6^{\circ} \mathrm{S}-8^{\circ} \mathrm{S}$ e os meridianos $34^{\circ} \mathrm{W}-38^{\circ} \mathrm{W}$. Incluído totalmente na zona tropical, o Estado apresenta clima quente com médias de temperatura que variam de $22{ }^{\circ} \mathrm{C}$ a $30{ }^{\circ} \mathrm{C}$ e índices pluviométricos relativamente elevados no litoral e baixo no interior do Estado. A Paraíba ocupa $0,66 \%$ de área territorial brasileira, destacando-se por apresentar condições de vento favoráveis à produção de energia eólica (Rodriguez, 2002; Mariano Neto, 2003). Na Fig. 1 é mostrada a localização da Paraíba, bem como suas mesorregiões.

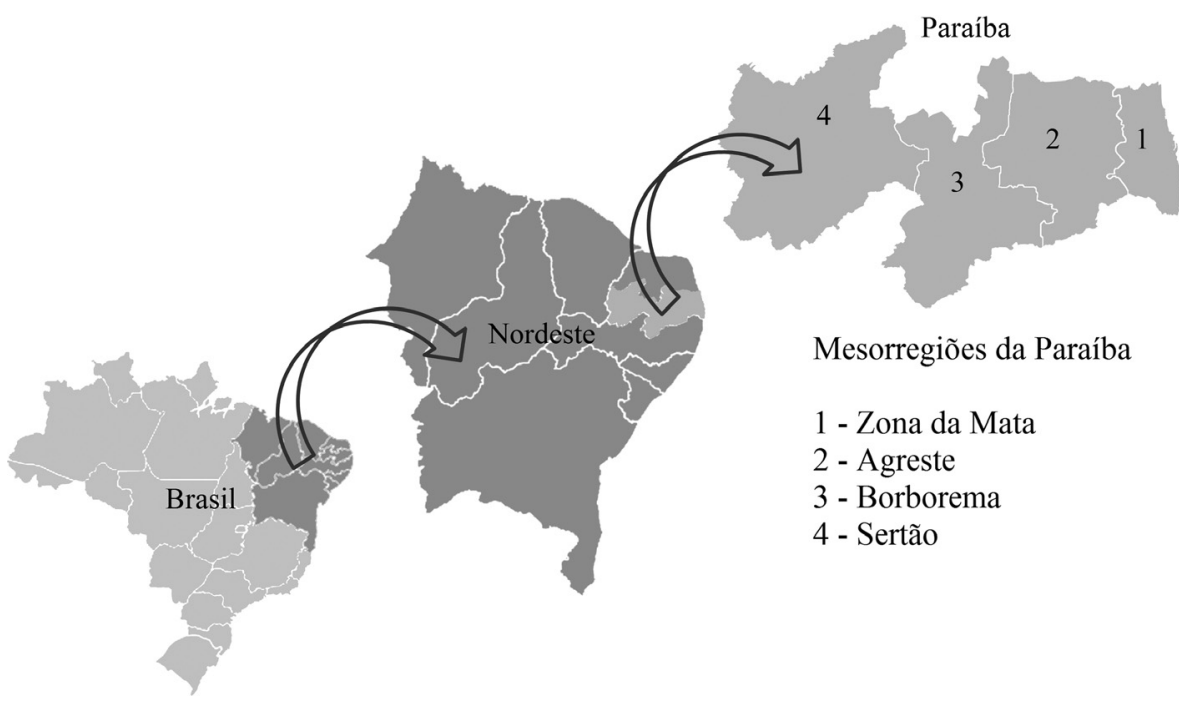

Figura 1 - Localização do Estado da Paraíba e suas mesorregiões. (Adaptado de redecidadedigital.com.br). 
Segundo a Agência Nacional de Energia Elétrica Aneel (2016), atualmente há na Paraíba 13 usinas eólicas em operação, todas instaladas na região da Zona da Mata. Juntas elas produzem um total de $69 \mathrm{MW}$, correspondente a cerca de $10,5 \%$ de toda energia produzida no estado.

De acordo com Sauer et al. (2006), o Brasil oferece excelentes sítios para instalação de parques eólicos, sendo que as melhores áreas se encontram ao longo da costa e nas áreas altas do interior do país. Nesse contexto, a Paraíba é um Estado privilegiado tanto pela localização geográfica, pois está em uma área banhada pelos ventos Alísios, que são praticamente constantes em direção e velocidade, quanto pela topografia que favorece sua distribuição no Estado.

A proximidade/afastamento da Zona de Convergência Intertropical (ZCIT) da área de estudo atua como um dos fatores de intensificação/desintensificação dos ventos. Juntamente com a migração da ZCIT ocorre o deslocamento da Alta Subtropical do Atlântico Sul (ASAS) cuja configuração faz com que o vento de grande escala sopre paralelo à costa leste do Nordeste e com maior (Hastenrath e Heller, 1977; Kousky e Chu, 1978; Ferreira e Mello, 2005). Além disso, os mecanismos de brisas marítimas no litoral e de vale-montanha no continente, formados pelo gradiente de temperatura originado a partir das diferenças de aquecimento, contribuem fortemente para o aumento na intensidade e na variação da direção dos ventos alísios (Silva, 2003; Valença, 2010).

A Paraíba é um dos estados brasileiros que ainda não dispõem de um atlas eólico. De certa forma isso acaba dificultando a exploração de áreas com alto potencial eólico. Saber como o vento se comporta a curto/longo prazo é muito importante quando se quer aproveitar esse recurso para geração de energia. Diante disso, os modelos numéricos podem ser usados como ferramentas na investigação inicial desses locais.

\subsection{Modelos numéricos utilizados}

Neste trabalho foram utilizados dois modelos numéricos de mesoescala. Um dos modelos utilizados foi o BRAMS, na versão 4.2. O BRAMS foi desenvolvido a partir do Modelo RAMS, que tem sua estrutura básica descrita por Pielke et al. (1992). O outro modelo utilizado foi WRF, na versão 3.4. O WRF é um modelo de previsão numérica do tempo, concebido para aplicações operacionais do tempo e investigação de fenômenos atmosféricos de mesoescala. A descrição sobre a arquitetura e desempenho do WRF pode ser encontrada em Michalakes et al. (2004).

\subsection{Descrição dos experimentos}

Os modelos foram integrados com duas grades aninhadas. A grade externa, com $16 \mathrm{~km}$ de resolução, cobre parte do Nordeste e do Atlântico e a grade interna, com resolução de $4 \mathrm{~km}$, cobre toda a Paraíba.

Os esquemas de parametrização usados são apresentados na Tabela 1 para cada modelo, sendo ativados tanto para a grade interna como para a externa, exceto nos experimentos realizados com o WRF, onde se verificou melhores resultados quando a parametrização de cúmulos foi desativada para a grade interna, tendo em vista a formação demasiada de nuvens quando esta parametrização estava ativa para referida grade. Os dados utilizados como entrada para os modelos foram os dados de reanálise do NCEP/NCAR de $0,75^{\circ}$ de resolução.

Quanto aos níveis verticais, os modelos foram integrados com 42 e 38 níveis, para o BRAMS e o WRF, respectivamente com nudging de 6 horas. Foram produzidas saídas a cada hora, de modo que as médias são calculadas com base em mais de 700 valores/mês para cada ponto.

As torres anemométricas não podem ter suas coordenadas geográficas reveladas por questão de confidencialidade de dados. Para efeito didático elas serão referenciadas com o nome da mesorregião onde se encontram instaladas, sendo doravante chamadas Torre Agreste, Torre Borborema e Torre Sertão, cujas características dos locais de instalação estão dispostas na Tabela 2.

Com base nos dados de velocidade do vento observados e simulados pelos modelos BRAMS e WRF, foram analisados os ciclos mensal e diário médios, o perfil vertical e a distribuição de Weibull.

O perfil vertical foi calculado para cada localidade utilizando a lei de potência, pois de acordo com Lopes (2010), o perfil vertical completo é melhor aproximado por essa lei:

Tabela 1 - Esquemas de parametrizações utilizados nos experimentos.

\begin{tabular}{|c|c|c|}
\hline \multirow[t]{2}{*}{ Parametrizações } & \multicolumn{2}{|l|}{ Modelo } \\
\hline & BRAMS & WRF \\
\hline Microfísica & Walko et al. (1995) & Lin et al. (1983) \\
\hline Convecção de Cúmulos & Cov. Rasa: Souza (1999) Conv. Profunda: Grell - Dévényi (2002) & Grell-Dévényi esemble (2002) \\
\hline Radiação de Onda Curta & Chen e Cotton (1983) & RRTMG (Mlawer et al., 1997) \\
\hline Radiação de Onda Longa & Chen e Cotton (1983) & RRTMG (Mlawer et al., 1997) \\
\hline Camada Limite Planetária & Mellor e Yamada (1982) & YSU (Hong et al., 2006) \\
\hline
\end{tabular}


Tabela 2 - Características geográficas e climatológicas do local das torres anemométricas.

\begin{tabular}{lccccc}
\hline Torres anemométricas & Altitude $(\mathrm{m})$ & Terreno & Vegetação & Temperatura média $\left({ }^{\circ} \mathrm{C}\right)$ & Precipitação média anual $(\mathrm{mm})$ \\
\hline Torre Agreste & 500 & Pequena depressão & Caatinga & 25 & 750 \\
Torre Borborema & 500 & Plano & Caatinga & 26 & 512 \\
Torre Sertão & 800 & Montanhoso & Caatinga & 28 & 736 \\
\hline
\end{tabular}

$$
u(z)=u\left(z_{r}\right)\left(\frac{z}{z_{r}}\right)^{\alpha}
$$

em que $z_{r}$ é a altura de referência, $u\left(z_{r}\right)$ é a velocidade do vento para essa altura e $\alpha$ é o expoente de camada limite obtido a partir de (Manwell et al., 2002; Camelo et al., 2010):

$$
\alpha=0,096\left(\log _{10} z_{0}\right)+0,016\left(\log _{10} z_{0}\right)^{2}+0,24
$$

A função densidade de probabilidade da distribuição de Weibull para uma variável aleatória $x$, contínua e independente, que se distribui de acordo com o modelo de Weibull, é dada por:

$$
f(x)=\left(\frac{k}{c}\right)\left(\frac{x}{c}\right)^{k-1} \exp \left[\left(-\frac{x}{c}\right)^{k}\right]
$$

em que $c$ e $k$ são os parâmetros de escala e de forma, respectivamente. $\mathrm{O}$ fator de forma $k$ da distribuição de Weibull para valores entre um e dez, pode ser obtidos a partir da equação abaixo (Manwell et al., 2002; Dias, 2010):

$$
k=\left(\frac{\sigma_{v}}{V m}\right)^{-1,086}
$$

em que $\sigma_{v}$ é o desvio padrão, e $V m$ é a velocidade média.

Conhecendo o valor de $k$ calculado com a Eq. (4), o valor do parâmetro de escala $c$ é obtido usando a seguinte aproximação:

$$
c=V m\left(0,568+\frac{0,433}{k}\right)^{\frac{-1}{k}}
$$

\subsection{Análise estatística}

De acordo com Weber et al. (1982), De Maria (2007), Cunha (2008) entre outros, a melhor forma de avaliar um modelo numérico é utilizando um conjunto de índices estatísticos (Lima et al., 2012). Neste caso utilizou-se: o Viés, o Erro Absoluto Médio (EA), o Erro Quadrático Médio $(E Q M)$ e o Índice de Correlação.

O Viés é calculado a partir de:

Viés $=\frac{1}{N} \sum_{i=1}^{n}\left(\phi_{i}-\phi_{0}\right)$

O Erro Absoluto Médio (EA) é dado por:

$$
E A=\frac{1}{N} \sum_{i=1}^{n}\left|\phi_{i}-\phi_{0}\right|
$$

O Erro Quadrático Médio $(E Q M)$ é obtido a partir de:

$$
E Q M=\left[\frac{1}{N} \sum_{i=1}^{n}\left(\phi_{i}-\phi_{0}\right)^{2}\right]^{1 / 2}
$$

em que $N$ é o número de dados, $\phi_{i}$ é o valor simulado e $\phi_{0}$ é o valor observado.

O coeficiente de correlação estatística ou coeficiente de correlação de Pearson $(r)$ é dado por:

$$
r=\frac{\sum\left(\phi_{i}-\bar{\phi}_{i}\right)\left(\phi_{0}-\bar{\phi}_{0}\right)}{\sqrt{\left[\sum\left(\phi_{i}-\bar{\phi}_{i}\right)^{2}\right]\left[\sum\left(\phi_{0}-\bar{\phi}_{0}\right)^{2}\right]}}
$$

Segundo Devore (2006) essa correlação pode variar de muito fraca a muito forte de acordo com os intervalos de $r$ contidos na Tabela 3. No entanto, antes de tirar qualquer conclusão sobre os valores dos coeficientes de correlação é necessária a aplicação de um teste estatístico para conhecer o grau real de ligação entre as variáveis analisadas (Lima, 2011).

O teste estatístico utilizado foi o teste de significância $t$ de Student, com os seguintes valores do parâmetro $t$ :

$$
t=\frac{r \sqrt{N-2}}{\sqrt{1-r^{2}}}
$$

O coeficiente de correlação crítico $\left(r_{c}\right)$, valor para o qual se aceita ou não a hipótese estatística, pode ser extraído a partir da Eq. (10) e dado por:

$$
r_{c}=\sqrt{\frac{t^{2}}{(N-2)+t^{2}}}
$$

Tabela 3 - Coeficiente de correlação estatística ou coeficiente de correlação de Pearson.

\begin{tabular}{ll}
\hline Intervalos & Definição \\
\hline 0,00 a 0,19 & Correlação bem fraca \\
0,20 a 0,39 & Correlação fraca \\
0,40 a 0,69 & Correlação moderada \\
0,70 a 0,89 & Correlação forte \\
0,90 a 1,00 & Correlação bem forte \\
\hline
\end{tabular}

Fonte: Devore, 2006 
Neste trabalho utilizou-se uma série de dados de 30 dias. Assim, para a correlação desses dados, ou seja, para $N=30$, com 2 graus de liberdade tem-se $N-2=28$. Com base nessa informação e utilizando os valores tabelados de $t$, os coeficientes de correlação crítico $r_{c}$ calculados estão dispostos na Tabela 4.

O resultado obtido pode sugerir a aceitação da hipótese de nulidade do coeficiente ou não. Caso o coeficiente de correlação $r$ calculado seja igual ou superior ao valor encontrado com o valor do $t$ crítico para um determinado grau de liberdade e percentual de significância, a hipótese de nulidade é rejeitada e a tendência observada é verdadeira para aquele nível de significância obtido (Bruni, 2007; Menezes, 2010; Lima, 2011).

De modo geral, para cada caso é mostrada a evolução temporal da velocidade, o que fornecerá uma ideia da variabilidade do vento para o mês, e o ciclo diário médio, o que dará ideia dos horários que, em média, apresentam maior e menor velocidade do vento. Por fim, os índices

Tabela 4 - Coeficiente de correlação crítico para $N-2=28$.

\begin{tabular}{lcc}
\hline Significância & $T^{1}$ & $r_{c}$ \\
\hline $90 \%$ & 1,313 & 0,24 \\
$95 \%$ & 1,701 & 0,31 \\
$99 \%$ & 2,467 & 0,42 \\
\hline
\end{tabular}

${ }^{1}$ Fonte: Barbetta, 2010. estatísticos serão apresentados e discutidos, bem como a adequação dos resultados de cada modelo a distribuição de Weilbull.

\section{Resultados}

\subsection{Estudo de caso: Setembro de 2010}

Como descrito na metodologia o estudo de caso foi realizado para o mês de setembro de 2010. Lembrando-se que as torres anemométricas são referenciadas com o nome da mesorregião onde se encontram instaladas.

\subsubsection{Perfil vertical}

A Fig. 2 traz o perfil vertical de velocidade do vento, obtido a partir da Lei de potência (Eq. (1)), utilizando dados de velocidade do vento das torres anemométricas (linha sólida), do WRF (linha tracejada) e do BRAMS (linha pontilhada). A fim de conseguir um perfil mais condizente com as velocidades observadas adotou-se como altura de referência $z_{r}=70 \mathrm{~m}$ e a velocidade de referência $u\left(z_{r}\right)$ a velocidade do vento para essa altura, tanto para os dados observados quanto para os dados extraídos dos modelos, tendo em vista que utilizando a altura de referência recomendada pela Organização Mundial de Meteorologia OMM, ou seja, $10 \mathrm{~m}$, a velocidade estimada divergia bastante da observada.

$\mathrm{O}$ comprimento de rugosidade $z_{0}$ mais adequado às condições do terreno onde as torres estão instaladas é
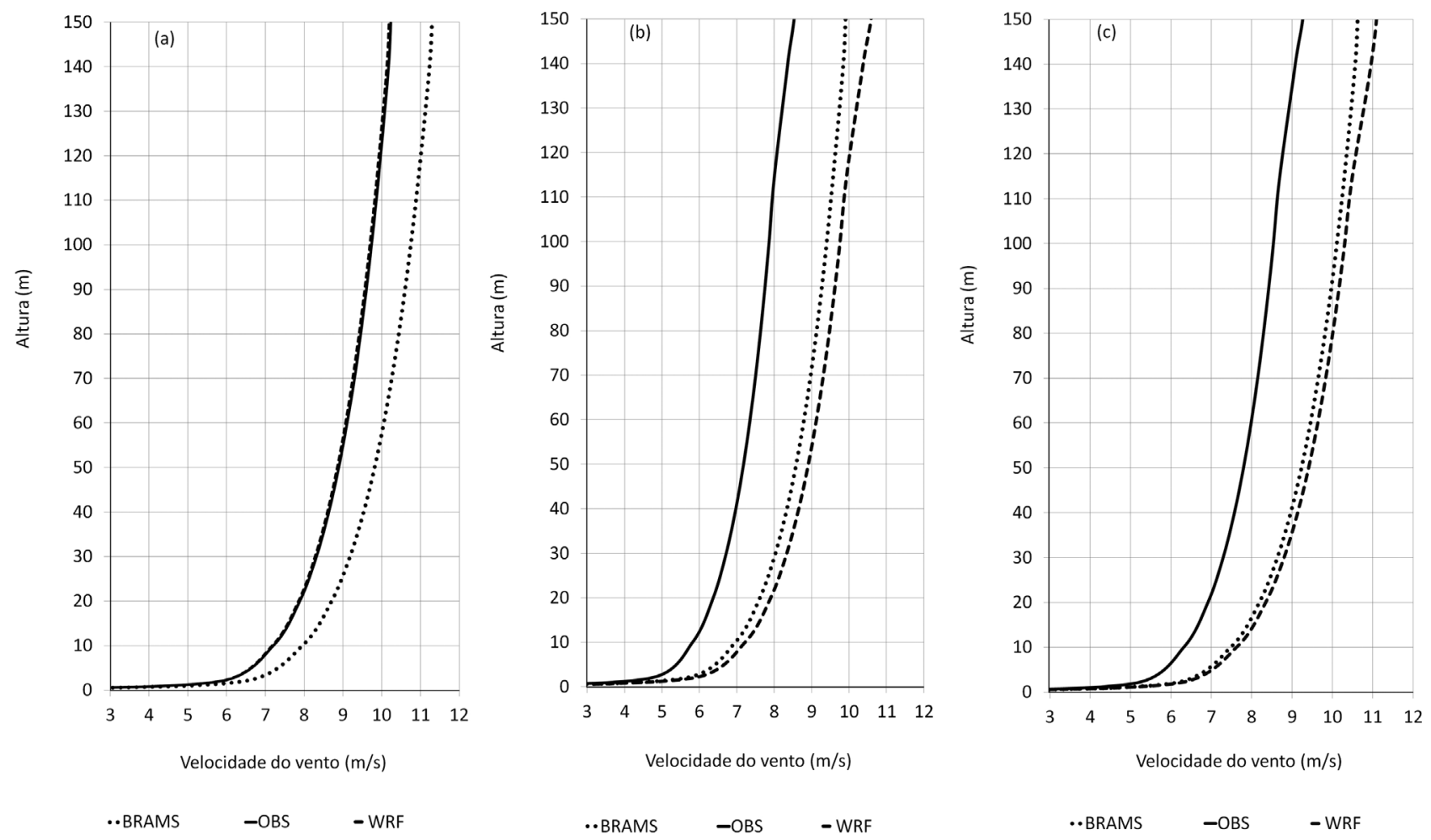

Figura 2 - Perfil vertical da velocidade do vento com a altura para setembro de 2010 para a localidade da: (a) Torre Agreste, (b) Torre Borborema e (c) Torre Sertão. 
$z_{0}=0,03 \mathrm{~m}$. Portanto, utilizando a Eq. (2), encontra-se para o expoente da camada limite o valor de $\alpha=0,13$, concordando com o valor apresentado em outros estudos, como Rohatgi (1994).

Para a Torre Agreste (Fig. 2a) nota-se boa concordância entre o perfil vertical do vento gerado com dados do WRF (linha tracejada) e o perfil gerado com os dados observados (linha sólida). No caso do BRAMS (linha pontilhada) a concordância existe para as velocidades de até $6 \mathrm{~m} / \mathrm{s}$. Após esta velocidade, o BRAMS apresenta um desvio revelando a superestimativa das velocidades pelo modelo.

Seguindo a mesma linha, têm-se nas Figs. $2 b$ e $2 c$ os perfis verticais para as Torres Borborema e Sertão, respectivamente. Em ambos os casos, percebe-se que há uma superestimativa dos perfis gerados pelos modelos em comparação ao observado (linha sólida). No entanto, há boa concordância entre os dados simulados e observados para velocidades abaixo dos $5 \mathrm{~m} / \mathrm{s}$. A partir daí os modelos apresentam uma tendência em superestimar a velocidade do vento à medida que cresce a altura, mostrando-se o BRAMS (linha pontilhada) ligeiramente menos divergente que o WRF (linha tracejada) em relação ao perfil observado (linha sólida) para as duas regiões.

Essa diferença notável entre os perfis simulados pelo WRF (linha tracejada) para a área da Torre Agreste e as outras duas áreas, se deve, muito provavelmente, ao fato do modelo ter simulado de forma mais eficaz os dados de velocidade do vento para o ponto onde a torre do Agreste está localizada, uma vez que os dados simulados foram extraídos em pontos cujas coordenadas geográficas correspondem às coordenadas de localização de cada torre.

\subsubsection{Ciclo mensal}

Informações sobre o ciclo mensal médio trazem, entre outros benefícios, o conhecimento da variação mensal do vento, inferindo na potência mensal do local em questão. Assim, o ciclo mensal médio para o local da Torre Agreste é mostrado na Fig. 3. A princípio, os modelos apresentam comportamento semelhante entre si durante grande parte do período simulado. Com relação ao ciclo observado (linha sólida), nota-se que o BRAMS (linha pontilhada) tende a superestimar o observado (linha sólida) durante quase todo o período, já o WRF (linha tracejada) tende a subestimar.

As maiores divergências, para ambos os modelos, estão entre os dias 11-13 e 19-20, quando se verifica um decréscimo dos valores observados enquanto os modelos apontam para valores máximos. No caso do BRAMS essa diferença é de cerca de $2,5 \mathrm{~m} / \mathrm{s}$ em relação ao observado para o dia 20. Acredita-se que isso possa ter ocorrido devido à dinâmica interna dos modelos terem respondido de forma diferente do esperado. Outra possível causa para isso, é que tenha ocorrido algum fenômeno local que interferiu na intensidade do vento e que os modelos não foram capazes de captar.

Em termos de máximo e mínimo o BRAMS (linha pontilhada) apresentou valores entre 7 e $12 \mathrm{~m} / \mathrm{s}$, aproximadamente. O WRF (linha tracejada) por sua vez, variou de pouco menos de $7 \mathrm{~m} / \mathrm{s}$ a $11 \mathrm{~m} / \mathrm{s}$. Tendo a velocidade observada variado da ordem de 7 a $11 \mathrm{~m} / \mathrm{s}$ ao longo do mês, percebe-se que para os extremos o WRF simulou valores mais realistas.

No geral, para esta localidade ambos os modelos conseguem reproduzir bem a variação média mensal da velocidade registrada para o período analisado, estando o ciclo simulado com o WRF mais próximo ao ciclo obser-

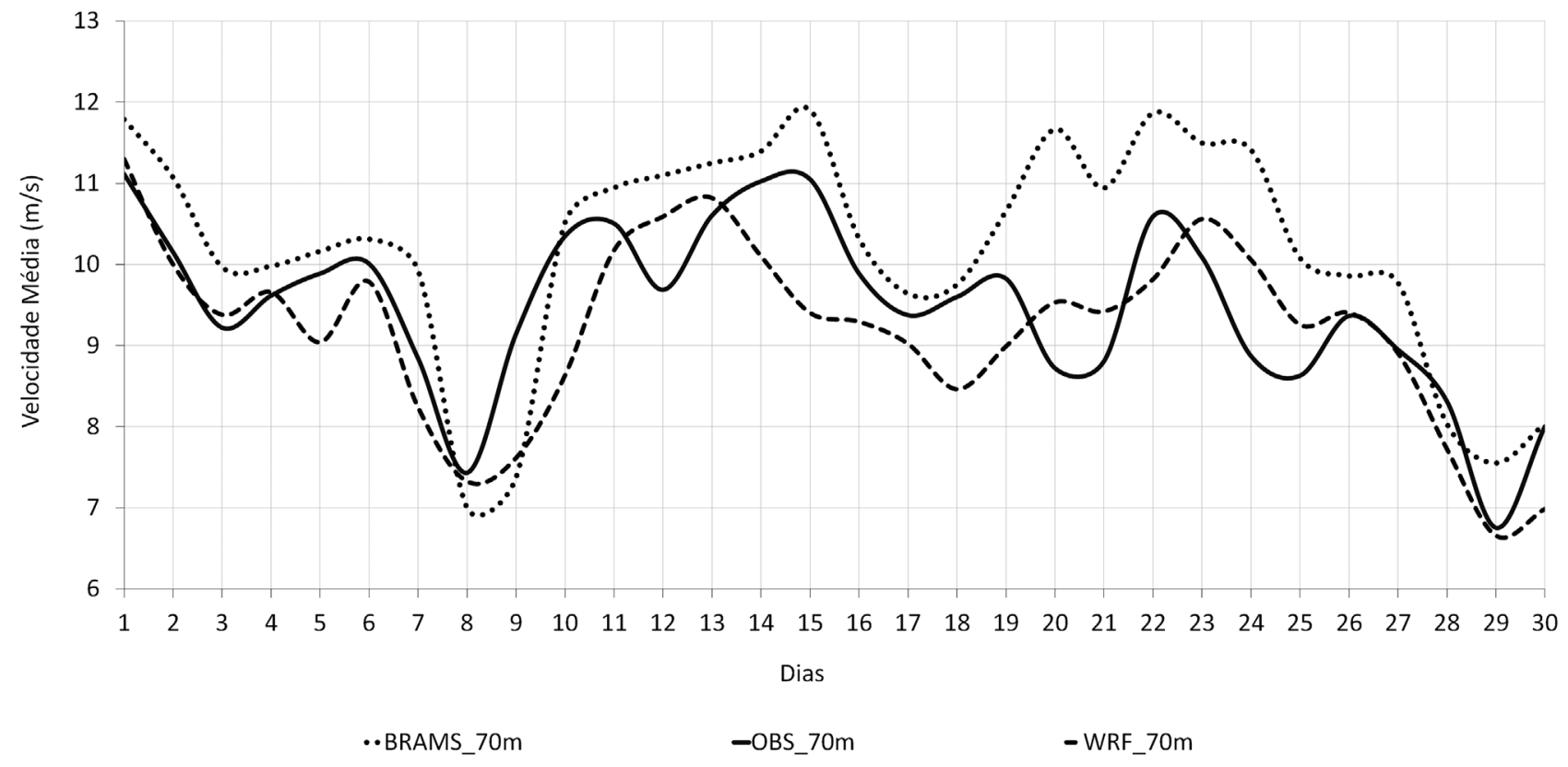

Figura 3 - Ciclo Mensal para setembro de 2010 para Torre Agreste a altura de $70 \mathrm{~m}$. 
vado, principalmente na segunda quinzena do mês, quando as diferenças de velocidade simulada e observada são visivelmente identificadas.

No caso da Torre Borborema (Fig. 4) nota-se a tendência de ambos os modelos em superestimar o observado (linha sólida). As maiores divergências estão na inversão de valores, ou seja, quando as velocidades observadas apontam para um decréscimo os valores simulados apontam para um crescimento e vice-versa. Essas inversões são verificadas entre os dias $13-15$ e $22-24$. Porém, em termos de magnitude e de máximo e mínimo o BRAMS mostra-se mais próximo do observado, uma vez que o WRF superestima o BRAMS em 1,5 m/s em média. Em resumo, para a Borborema, apesar da superestimativa, o BRAMS tende a aproximar-se mais do observado. É possível que isso seja devido ao fato do BRAMS simular melhor que o WRF a topografia local.

Para a localidade da Torre Sertão (Fig. 5), os modelos tendem a superestimar o observado (linha sólida) em média em $1,5 \mathrm{~m} / \mathrm{s}$, e apresentam um pequeno atraso em relação aos picos observados a partir da segunda quinzena do mês. Quanto as principais divergências, estas foram verificadas,

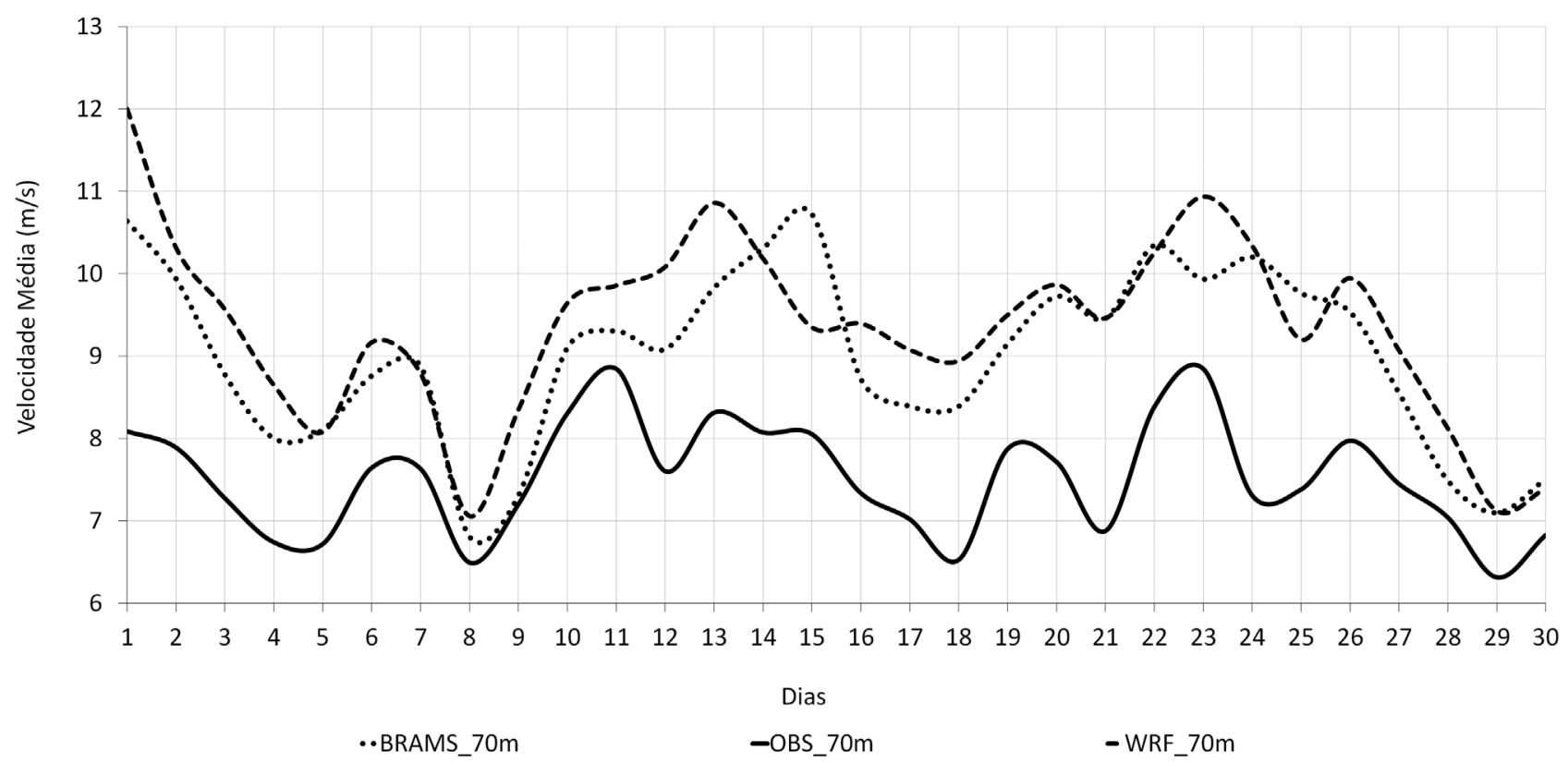

Figura 4 - Ciclo Mensal para setembro de 2010 para Torre Borborema a altura de $70 \mathrm{~m}$.

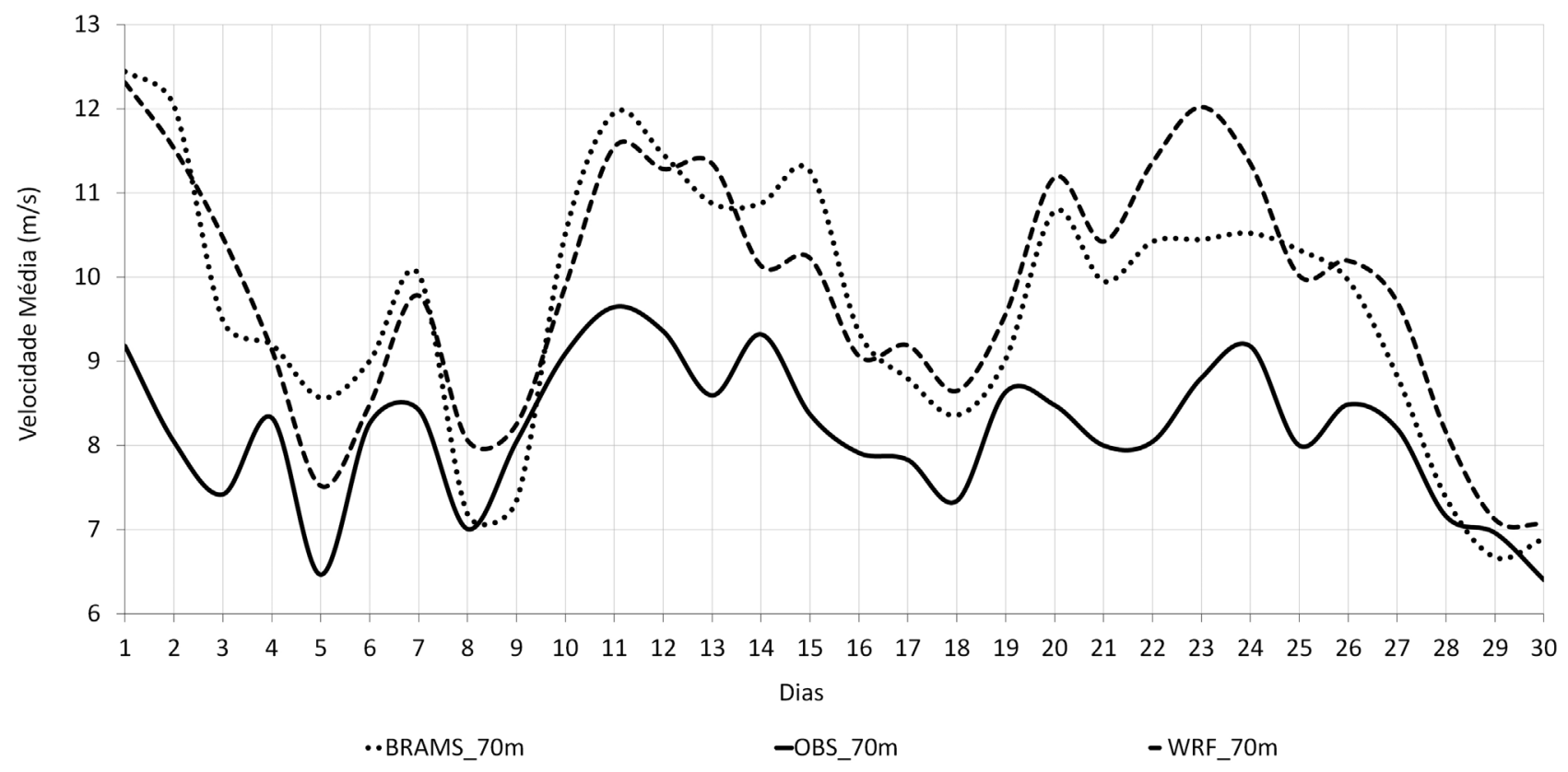

Figura 5 - Ciclo Mensal para setembro de 2010 para Torre Sertão a altura de $70 \mathrm{~m}$. 
por exemplo entre os dias 12 e 15 (WRF) e entre os dias 22 e 26 (BRAMS), quando os modelos não reproduzem a variação registrada pelo vento real. No tocante ao valor máximo os dois modelos apontam um valor cerca de $2,5 \mathrm{~m} / \mathrm{s}$ acima do observado. No entanto, o BRAMS reproduz com maior fidelidade o valor mínimo.

De modo geral, os modelos apresentam uma tendência de superestimar os ciclos mensais observados, exceto o WRF que para a Torre Agreste subestimou o ciclo mensal em parte do período simulado. No entanto, os modelos mostram-se capazes de acompanhar a variação da velocidade média mensal para ambas as localidades, apresentando algumas inversões de máximo/mínimo com relação ao ciclo observado, que podem ser devidas à ocorrência de algum fenômeno local que os modelos não conseguiram reproduzir.

\subsubsection{Ciclo diário}

Para os parques eólicos informações sobre o comportamento do vento ao longo do dia favorecem, dentre outras coisas, a tomada de decisão no que diz respeito, principalmente, aos períodos de manutenção das máquinas, uma vez que passam a ser conhecidos os horários que, em média, apresentam maior e menor velocidade do vento, ou seja, períodos de maior e menor produção de energia, evitando assim os horários de maior rendimento e por consequência uma perda desnecessária na produção de energia.

Na Fig. 6 tem-se o ciclo diário para a Torre Agreste. Nota-se que, enquanto o BRAMS (linha pontilhada) superestima os valores observados durante quase todo o dia, com o WRF (linha tracejada) acontece o contrário, ou seja, ele subestima esses valores.

As maiores discrepâncias entre os dados simulados e o observado estão entre as 9-16 HL. Aparentemente, os modelos não estão conseguindo captar os efeitos radiativos (aquecimentos/resfriamento) responsáveis pela variação/estagnação do vento no intervalo em que é registrada a maior variação de temperatura devido à incidência de radiação solar para o mês em questão (setembro de 2010) de acordo com dados de temperatura e radiação coletados em estações meteorológicas (convencionais e automáticas) do INMET distantes cerca de $40 \mathrm{~km}$, cujas características geográficas e climatológicas assemelham-se a da região de instalação da Torre. Este intervalo vai de, aproximadamente, quatro horas após o nascer do sol (8-9 HL) até 2 horas após ser alcançada a temperatura máxima diária (15-16 HL). Nos demais horários os modelos tendem a acompanhar a variação diária do vento.

A análise gráfica revela que os maiores valores observados são registrados na parte da manhã e durante a noite, sendo o máximo obtido por volta das $8 \mathrm{HL}$. Para o BRAMS o máximo ocorre 2 horas depois do observado, já para o WRF o máximo ocorre justamente no horário em que é registrado o mínimo observado ( $14 \mathrm{HL})$. Apesar das divergências, é notável que o WRF acompanha o ciclo de velocidade média diário de forma mais concisa tanto na parte da manhã quanto à noite. A dificuldade que os modelos têm em reproduzir o ciclo diário entre às $8-16 \mathrm{HL}$, pode estar relacionada ao fato destes não estarem bem configurados ou não serem totalmente eficientes na reprodução do vento em áreas com terrenos relativamente complexo como este onde a torre anemométrica está instalada.

No caso da Torre Borborema (Fig. 7) as observações (linha sólida) revelam um ciclo diário com velocidade máxima em torno dos $9 \mathrm{~m} / \mathrm{s}$, por volta das $18 \mathrm{HL}$, e mínima acima de $5,5 \mathrm{~m} / \mathrm{s}$ registrada às $4 \mathrm{HL}$. Quanto aos ciclos modelados, o BRAMS (linha pontilhada) simula seu máximo no mesmo horário do observado, já para o WRF (linha

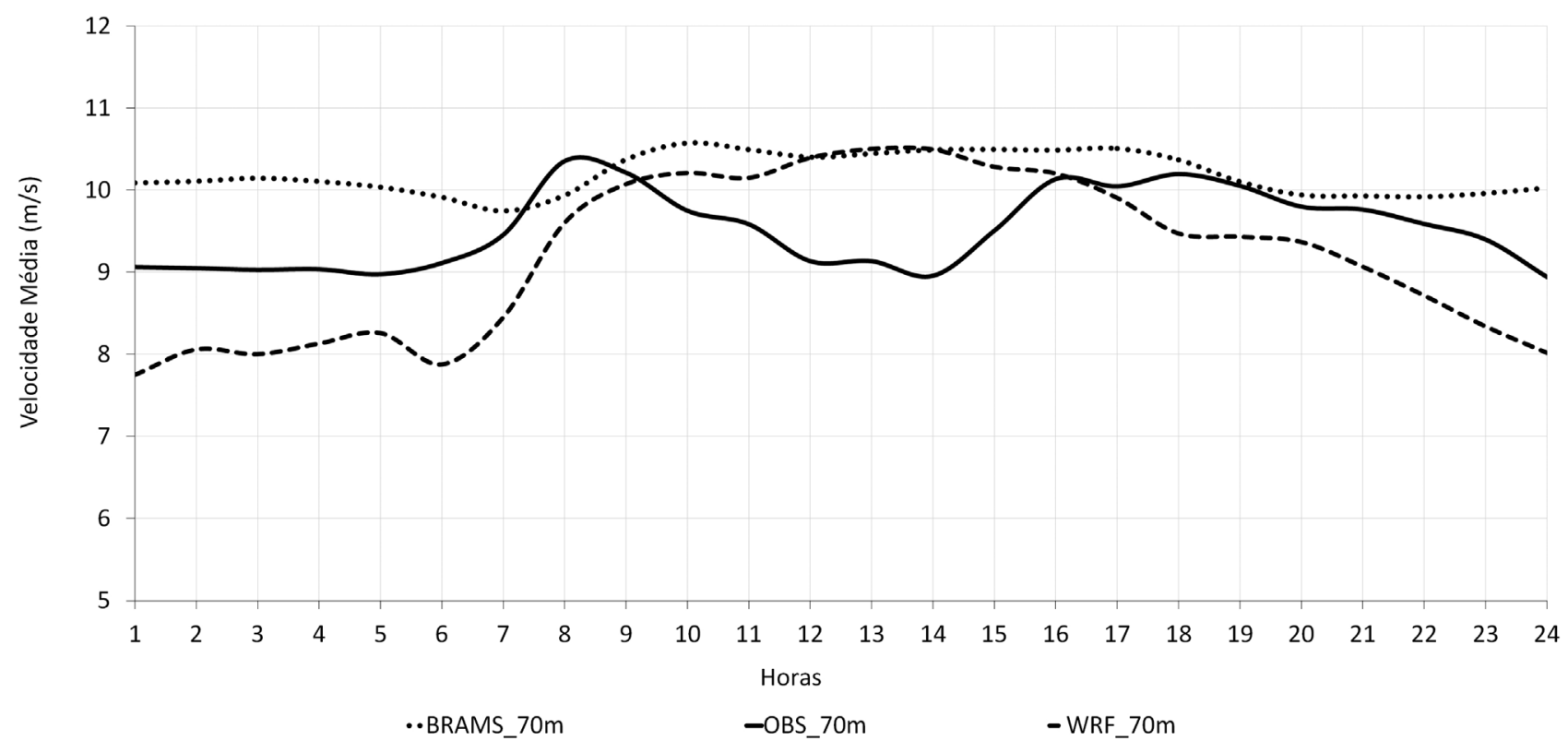

Figura 6 - Ciclo diário para setembro de 2010 para Torre Agreste a altura de $70 \mathrm{~m}$. 


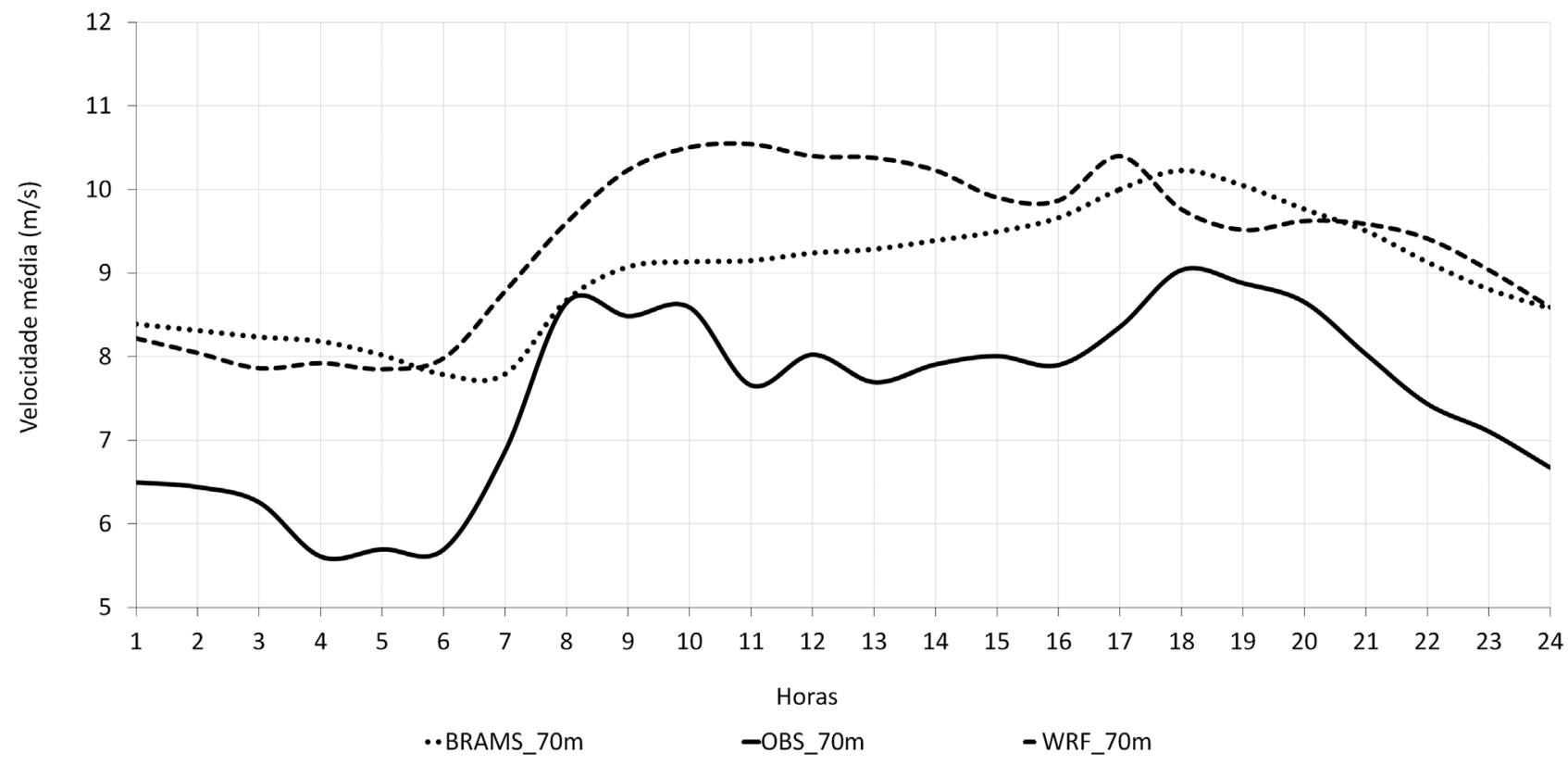

Figura 7 - Ciclo diário para setembro de 2010 para Torre Borborema a altura de $70 \mathrm{~m}$.

tracejada) o máximo é registrado 8 horas antes, às $10 \mathrm{HL}$. No tocante aos mínimos os modelos assinalam estes valores com 2 horas de atraso no caso do BRAMS e 1 hora antes no caso do WRF. Porém, os dois modelos apresentam um ciclo diário que se assemelha ao ciclo diário observado, mesmo superestimando o vento. De forma geral, o ciclo diário reproduzido pelo BRAMS mostrou-se mais condizente com relação ao ciclo diário observado, com máximo ocorrendo no mesmo horário do observado.

Para a Torre Sertão (Fig. 8) o ciclo diário apresenta um padrão típico de regiões montanhosas, com máximos ocorrendo durante a noite e mínimos durante o dia, configurando um padrão que os modelos, ainda que superestimando os valores observados, foram capazes de representar. Neste caso, os mínimos simulados e observado ocorrem no mesmo horário, por volta das $15 \mathrm{HL}$. Já os máximos simulados são verificados com $2 / 4$ horas de atraso, para o BRAMS/WRF. No que diz respeito à média, devido à pequena variação entre os valores simulados, tanto o BRAMS (linha pontilhada) quanto o WRF (linha tracejada) apresentaram uma média, aproximadamente, $1,5 \mathrm{~m} / \mathrm{s}$ acima da observada.

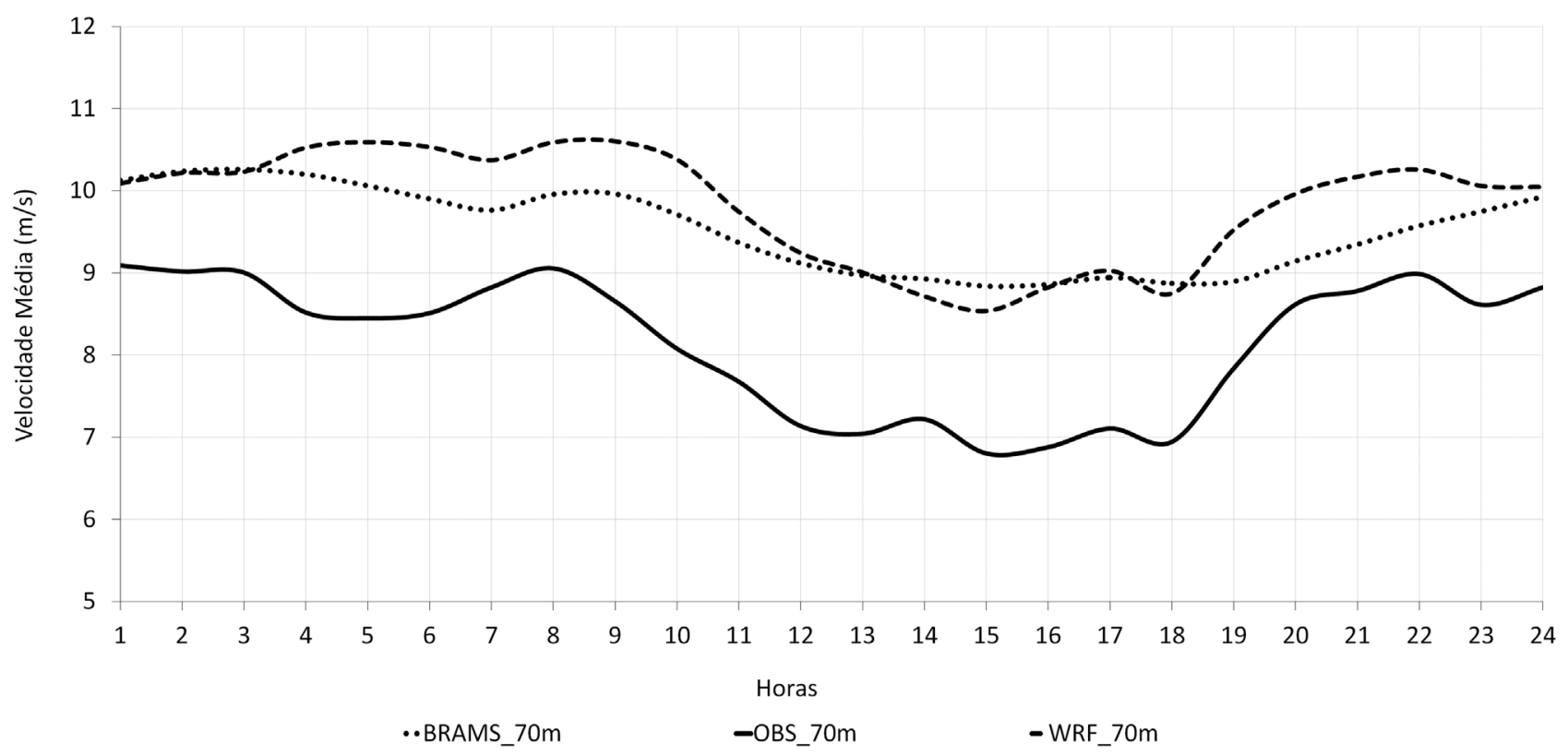

Figura 8 - Ciclo diário para setembro de 2010 para Torre Sertão a altura de $70 \mathrm{~m}$. 
De modo geral, os modelos conseguem, apesar da superestimativa, representar com maior coerência os ciclos diários para os dados registrados pela torre anemométrica instalada na mesorregião do Sertão em relação às outras regiões analisadas.

\subsubsection{Distribuição de Weibull}

A distribuição de Weibull se ajusta bem aos dados de velocidade do vento, particularmente no caso de velocidades superiores a $5 \mathrm{~m} / \mathrm{s}$ (Hennessey Jr, 1977; Justus et al., 1978; Pereira, 2008). Portanto é de se esperar que haja um bom ajuste tanto dos dados simulados bem como dos dados da torre, tendo em vista que os ciclos mensais e diários (Figs. 3-5 e 6-8, respectivamente) apontam velocidades acima de $5 \mathrm{~m} / \mathrm{s}$.

A distribuição de frequência da velocidade do vento para o local da Torre Agreste é visualizada na Fig. 9. A curva sobreposta às faixas de velocidade representa a distribuição de Weibull. Nota-se que as velocidades simuladas e as observadas ajustam-se à distribuição de Weibull, exceto os dados simulados pelo BRAMS (Fig. 9b) cuja distribuição parece não se ajustar muito bem. Acredita-se que isso tenha ocorrido devido provavelmente ao fato do valor mais frequente de velocidade do vento gerado pelo BRAMS $(11 \mathrm{~m} / \mathrm{s}$, aproximadamente $30 \%$ da distribuição), estar em média $9 \%$ acima dos outros dois valores de maior ocorrência (10 e $12 \mathrm{~m} / \mathrm{s}$, que correspondem a $24 \%$ e $18 \%$ da distribuição, respectivamente).

Analisando os gráficos da distribuição verifica-se que tanto o intervalo de velocidades mais frequentes $(9-11 \mathrm{~m} / \mathrm{s})$ quanto à moda $(10 \mathrm{~m} / \mathrm{s})$ são os mesmos encontrados para $\mathrm{o}$ vento observado (Fig. 9a) e o simulado pelo WRF (Fig. 9c). Porém há uma diferença de, aproximadamente, $3 \%$ a menos na faixa de velocidade de $10 \mathrm{~m} / \mathrm{s}$ para o WRF em relação aos dados observados.
Para a Torre Borborema, a distribuição de frequência da velocidade do vento (Fig. 10), revela que nessa região os ventos ajustam-se à distribuição de Weibull. Nota-se a existência de uma diferença entre o BRAMS (Fig. 10b) e os dados observados (Fig. 10a), de $1 \mathrm{~m} / \mathrm{s}$ a mais para o vento mais frequente gerado pelo modelo, porém a moda é $1 \mathrm{~m} / \mathrm{s}$ menor que a observada $(8 \mathrm{~m} / \mathrm{s})$. Para o WRF (Fig. 10c) os ventos mais frequentes estão entre $9-11 \mathrm{~m} / \mathrm{s}, 2 \mathrm{~m} / \mathrm{s}$ a mais que o observado, sendo a moda $10 \mathrm{~m} / \mathrm{s}$.

No caso da Torre do Sertão (Fig. 11), para os dados observados (Fig. 11a) a faixa de maior ocorrência é a que compreende os ventos com velocidades entre $8-10 \mathrm{~m} / \mathrm{s}$, para os modelos isto é verificado entre $9-11 \mathrm{~m} / \mathrm{s}$. Quanto às modas, os modelos apresentam valores um pouco mais elevados que a moda do vento observado $(9 \mathrm{~m} / \mathrm{s})$ sendo de $10 \mathrm{~m} / \mathrm{s}$, no caso do BRAMS (Fig. $11 \mathrm{~b}$ ) e $11 \mathrm{~m} / \mathrm{s}$ no do WRF (Fig. 11c). No geral, observando os gráficos para as três localidades, percebe-se que as curvas de distribuição apresentaram-se mais estreitas mostrando uma menor variação do vento.

Com relação aos parâmetros $k \mathrm{e} c$ da distribuição de Weibull, calculados a partir do método dos desvios e velocidades médias (Eqs. (6) e (7)), apresentados na Tabela 5, os valores mais próximos dos parâmetros de Weibull obtidos com os dados observados para a Torre Agreste são fornecidos pelo WRF.

Para a Torre Borborema, para o fator de escala $c$ o BRAMS aponta um valor mais coerente, no entanto o fator de forma $k$ é melhor para os dados do WRF. Sabendo que o parâmetro $c$ está relacionado às médias de velocidade do vento, era esperado que isso ocorresse, uma vez que nesta região as médias obtidas com BRAMS estão mais próximas das observadas. Para a Torre Sertão, tanto o fator de forma $k$ quanto o fator de escala $c$ obtidos com os dados do BRAMS
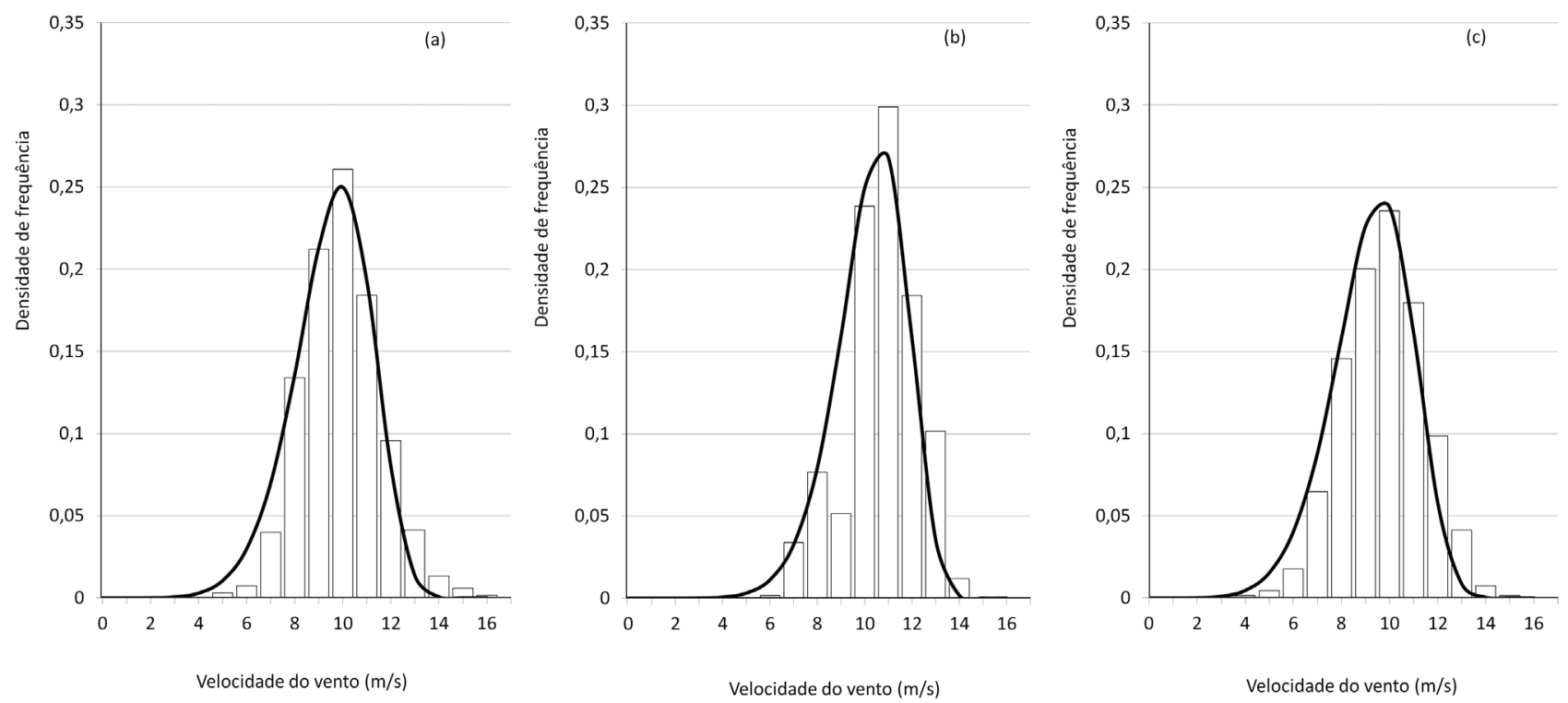

Figura 9 - Distribuição de Weibull para setembro de 2010 para Torre Agreste a 70 m de altura: (a) Observado, (b) BRAMS (c) WRF. 

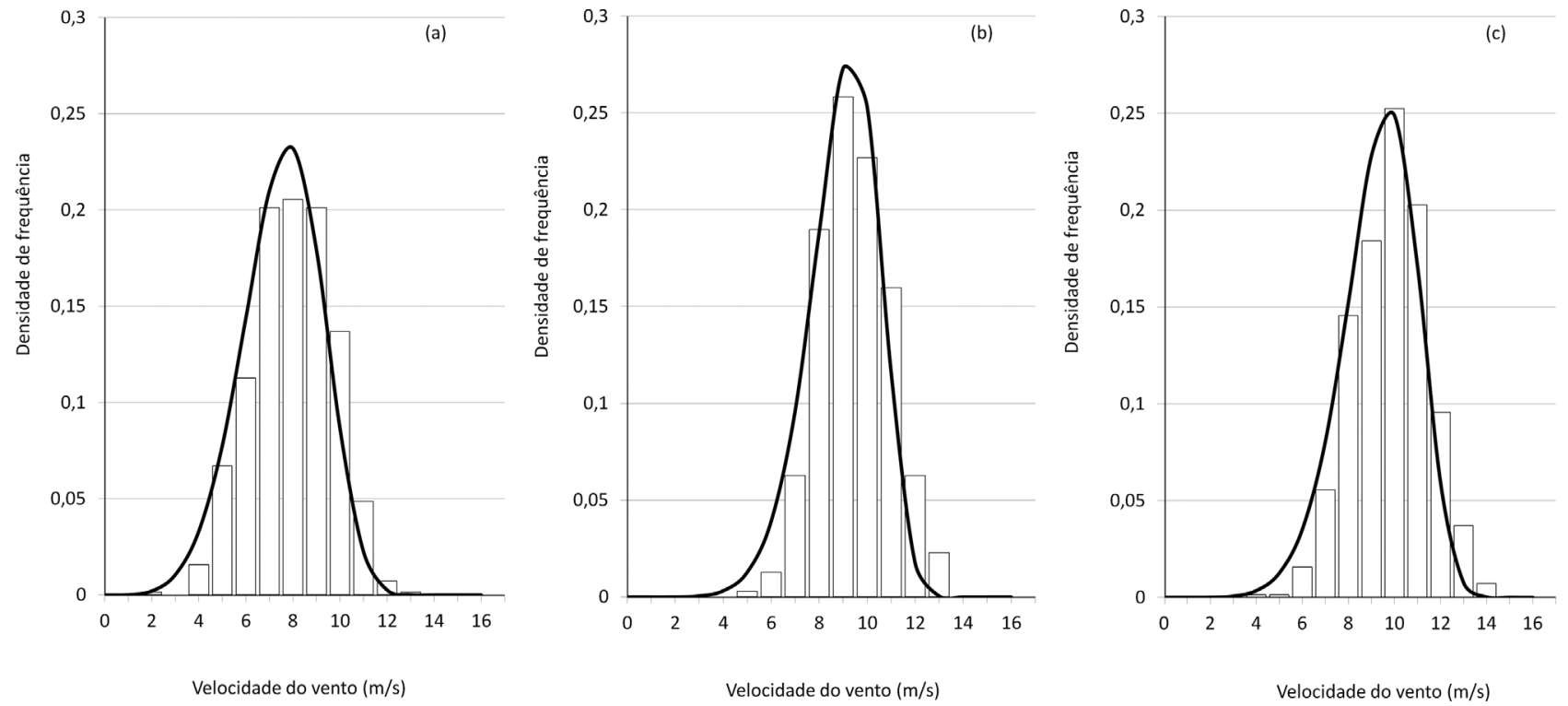

Figura 10 - Distribuição de Weibull para setembro de 2010 para Torre Borborema a 70m de altura: (a) Observado, (b) BRAMS (c) WRF.

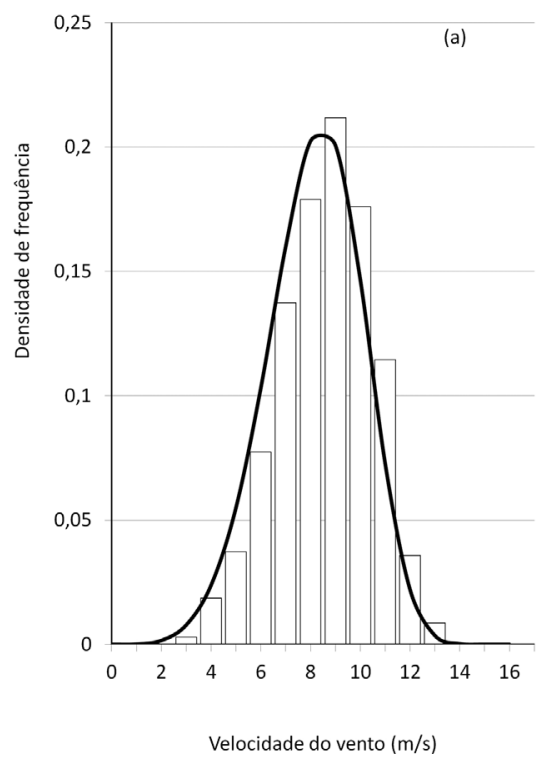

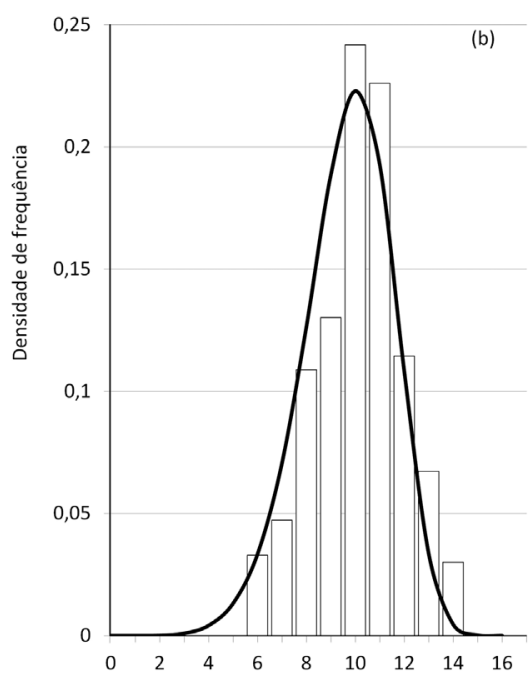

Velocidade do vento $(\mathrm{m} / \mathrm{s})$

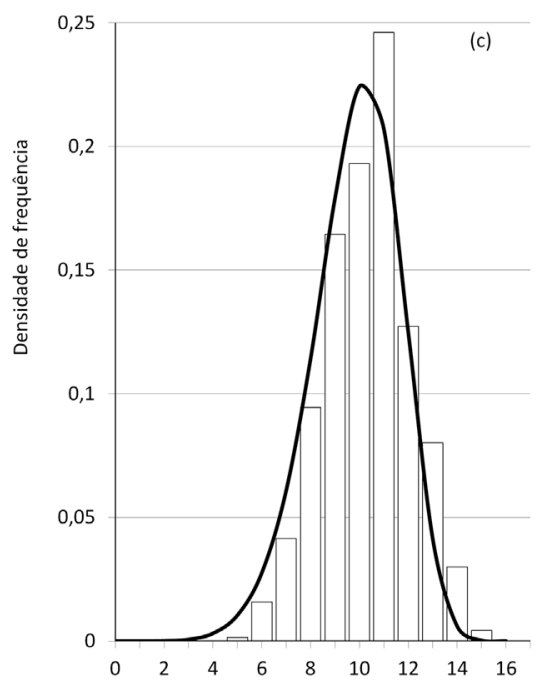

Velocidade do vento $(\mathrm{m} / \mathrm{s})$

Figura 11 - Distribuição de Weibull para setembro de 2010 para Torre Sertão a 70m de altura: (a) Observado, (b) BRAMS (c) WRF.

mostram-se mais coerentes em relação aos obtidos para os dados observados.

\subsection{5. Índices estatísticos}

Em estudos que envolvem dados de vento simulados e observados, é comum querer saber se há relação entre eles. O método usualmente conhecido para medir a correlação entre tais dados é o Coeficiente de Correlação Linear de Pearson $(r)$.

Na Fig. 12 têm-se as correlações entre os dados de velocidade média diária observados e os simulados para a Torre Agreste. A princípio, verifica-se que o coeficiente de determinação $\left(R^{2}\right)$ mostrou-se superior para os dados do
BRAMS em comparação com o WRF. Percebe-se que o coeficiente de determinação para o BRAMS (Fig. 12a) e o WRF (Fig. 12b) explica $61 \%$ e $57 \%$ da variabilidade dos dados observados, respectivamente.

Para a Torre Borborema (Fig. 13), diferente do obtido para a do Agreste, o coeficiente de determinação mostra-se mais elevado para o WRF, explicando, aproximadamente, $69 \%$ da variabilidade dos dados nesta região, enquanto o BRAMS apresenta coeficiente de determinação cerca de 8\% menor. Quanto aos coeficientes de correlação, esses indicam que há forte correlação entre os dados observados e simulados por ambos os modelos ( $r$ acima de 0,78 ), sendo mais elevado para o WRF. 
Tabela 5 - Parâmetros da distribuição de Weibull para setembro de 2010 a 70 m de altura.

\begin{tabular}{|c|c|c|c|c|c|c|}
\hline \multirow[t]{3}{*}{ Torres anemométricas } & \multicolumn{6}{|c|}{ Parâmetros de Weibull } \\
\hline & \multicolumn{3}{|c|}{$k$} & \multicolumn{3}{|c|}{$c(\mathrm{~m} / \mathrm{s})$} \\
\hline & OBS & BRAMS & WRF & OBS & BRAMS & WRF \\
\hline Torre Agreste & 6,84 & 8,07 & 6,48 & 10,18 & 10,84 & 9,90 \\
\hline Torre Borborema & 5,07 & 7,29 & 6,77 & 8,16 & 9,57 & 9,97 \\
\hline Torre Sertão & 4,92 & 6,21 & 6,43 & 8,88 & 10,37 & 10,55 \\
\hline
\end{tabular}
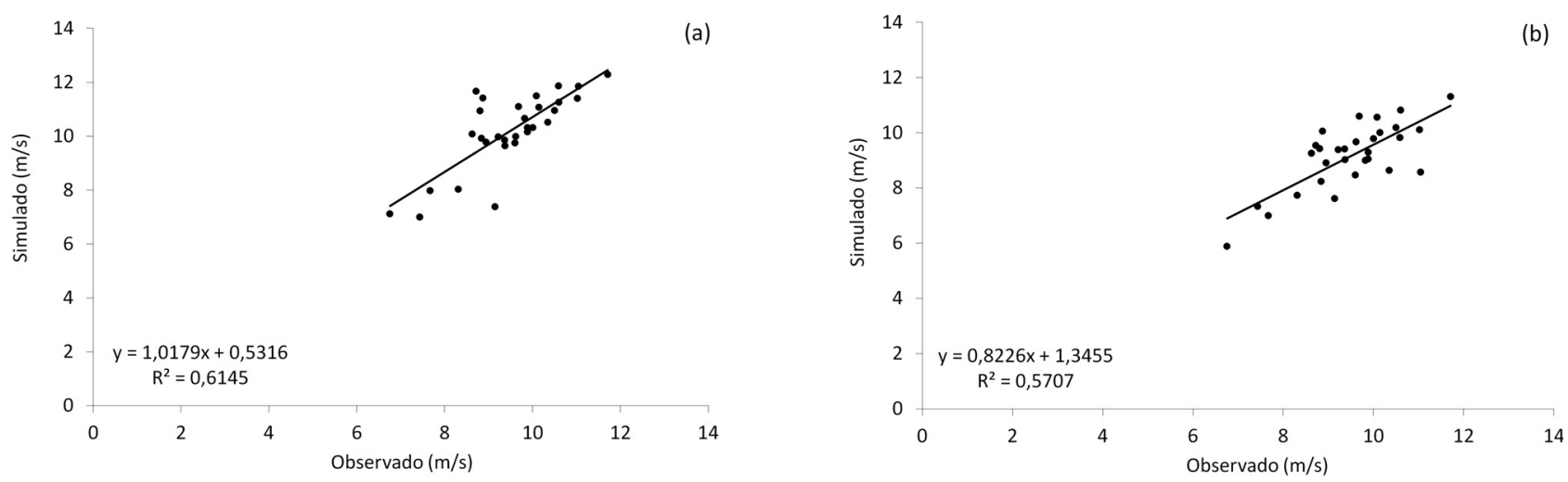

Figura 12 - Correlação linear para Torre Agreste a 70 m de altura entre dados observados e simulados pelos modelos: (a) BRAMS e (b) WRF.
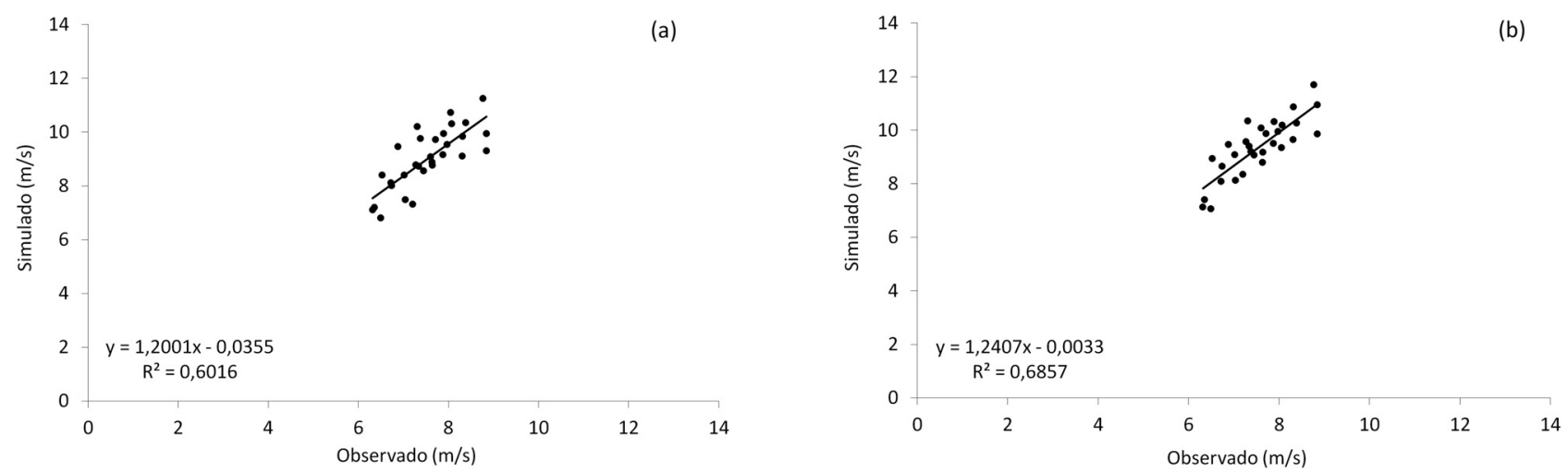

Figura 13 - Correlação linear para Torre Borborema a $70 \mathrm{~m}$ de altura entre dados observados e simulados pelos modelos: (a) BRAMS e b) WRF.

No caso da Torre do Sertão (Fig. 14), os coeficientes de determinação encontrados explicam, respectivamente, $62 \%$ e $60 \%$ da variabilidade dos dados para o BRAMS (Fig. 14a) e o WRF (Fig. 14b), uma diferença de 2\% a mais para o coeficiente de determinação obtido para o BRAMS. Com relação aos coeficientes de correlação, esses estão acima de 0,77 , sugerindo que há forte correlação entre os dados observados e os simulados por ambos os modelos.

Os coeficientes de correlação de Pearson $(r)$, dispostos na Tabela 6 , revelam que ambos os modelos apresentam uma forte correlação com os dados observados na altura analisada, uma vez que os valores de $r$ estão acima de 0,76 .

De modo geral, os maiores coeficientes de determinação, bem como os coeficientes de correlação, para os dados do BRAMS foram obtidos para a localidade do Sertão. No caso do WRF isso é verificados para os coeficientes encontrados para a Torre da Borborema. Tal fato pode ser atribuído, dentre outros fatores, a capacidade que $o$ modelo tem de representar a circulação para áreas como essas onde as torres estão localizadas.

Para verificar se as correlações obtidas entre os dados de vento observados e simulados são significativas, utilizou-se o teste de $t$ de Student. Com base nos valores de $t$, para uma série de dados de 30 dias $(N=30)$ com 2 graus de liberdade, e do coeficiente de correlação crítico $\left(r_{c}\right)$ contidos na Tabela 3, verifica-se que os coeficientes de correlação $(r)$ encontrados são superiores aos valores de $r_{c}$ para o nível de significância de 99\%. Portanto, todos os coeficien- 

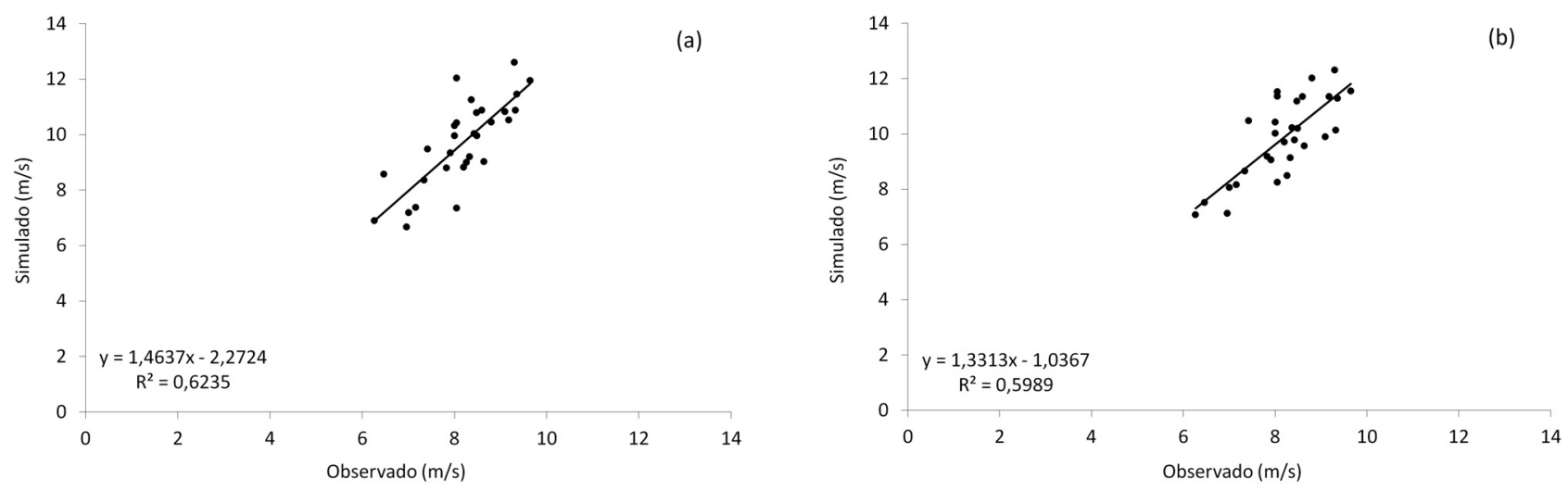

Figura 14 - Correlação linear para Torre Sertão a 70 m de altura entre dados observados e simulados pelos modelos: (a) BRAMS e b) WRF.

tes de correlação obtidos para os dados simulados com ambos os modelos apresentaram significância estatística ao nível de 99\%. Logo, pode-se concluir que há evidências estatísticas suficientes para afirmar que as séries de dados observados e as séries de dados simulados pelos dois modelos, estão bem correlacionadas.

Quanto aos erros, os resultados obtidos são mostrados na Tabela 7. Analisando os resultados do Viés, nota-se que o BRAMS superestimou os resultados para as três localidades, já o WRF subestimou os resultados para a localidade do Agreste em $0,34 \mathrm{~m} / \mathrm{s}$. Nota-se também que a maior diferença foi encontrada para os resultados do WRF para a localidade da Borborema $(1,81)$. Esses resultados são notáveis quando se visualizam os gráficos dos ciclos mensais e diários correspondentes as referidas localidades (Figs. 7-8 e 10-11).

Com relação aos erros absoluto médio $(E A)$ e quadrático médio $(E Q M)$, verifica-se que os resultados do WRF foram os melhores para a localidade do Agreste $(E A=0,68 \mathrm{~m} / \mathrm{s}$ e $E Q M=0,86)$ e os piores para a localidade da Borborema $(E A=1,81 \mathrm{~m} / \mathrm{s}$ e $E Q M=1,92 \mathrm{~m} / \mathrm{s})$. No caso da Torre do Sertão, o BRAMS obteve os melhores resultados.

Diante do exposto, infere-se que o BRAMS teve melhor desempenho para as localidades situadas nas regiões da Borborema e do Sertão, ao passo que o WRF mostrou-se melhor para a do Agreste. Esses resultados concordam com os resultados encontrados por Wang et al. (2011), que afirmam não existir um modelo único que seja melhor em todos os casos.

Levando em consideração os valores médios de velocidade do vento simulados e os índices obtidos na análise estatística, os resultados das simulações aqui apresentadas sugerem que os modelos são capazes de representar o comportamento do vento em média de forma satisfatória apesar da dificuldade que eles apresentam em reproduzir as

Tabela 6 - Coeficientes de determinação e correlação obtidos entre as séries de dados observados e simulados para setembro de 2010 a $70 \mathrm{~m}$ de altura.

\begin{tabular}{lcccccc}
\hline Torres anemométricas & \multicolumn{3}{c}{ Coeficientes } \\
\cline { 2 - 5 } & \multicolumn{2}{c}{ Determinação $\left(R^{2}\right)$} & & & \multicolumn{2}{c}{ Correlação $(r)$} \\
\cline { 2 - 3 } \cline { 5 - 6 } & BRAMS & WRF & & BRAMS & WRF \\
\hline Torre Agreste & 0,61 & 0,57 & & 0,78 & 0,76 \\
Torre Borborema & 0,60 & 0,69 & & 0,78 & 0,83 \\
Torre Sertão & 0,62 & 0,60 & & 0,79 & 0,77 \\
\hline
\end{tabular}

Tabela 7 - Índices estatísticos obtidos para as séries de dados observados e simulados para setembro de 2010 a $70 \mathrm{~m}$ de altura.

\begin{tabular}{|c|c|c|c|c|c|c|}
\hline \multirow[t]{3}{*}{ Torres anemométricas } & \multicolumn{6}{|c|}{ Índices estatísticos } \\
\hline & \multicolumn{3}{|c|}{ BRAMS - OBS } & \multicolumn{3}{|c|}{ WRF - OBS } \\
\hline & Viés & $E A(\mathrm{~m} / \mathrm{s})$ & $E Q M(\mathrm{~m} / \mathrm{s})$ & Viés & $E A(\mathrm{~m} / \mathrm{s})$ & $\operatorname{EQM}(\mathrm{m} / \mathrm{s})$ \\
\hline Torre Agreste & 0,70 & 0,87 & 1,12 & $-0,34$ & 0,68 & 0,86 \\
\hline Torre Borborema & 1,47 & 1,47 & 1,64 & 1,81 & 1,81 & 1,92 \\
\hline Torre Sertão & 1,51 & 1,58 & 1,83 & 1,67 & 1,67 & 1,92 \\
\hline
\end{tabular}


variações de pequena escala de tempo. Segundo Lima (2011) esta dificuldade pode ser atribuída ao fato de os fatores locais não estarem bem representados dentro do modelo, o que poderia ser corrigido com a utilização de um modelo de microescala, bem como a utilização de dados de superfícies de fontes diferentes dos utilizados neste trabalho, além de melhores resoluções espaciais e com alta qualidade.

\section{Conclusões}

Diante dos resultados, conclui-se que há uma boa concordância entre o perfil vertical estimado com dados do WRF e o perfil estimado com os dados observados para a localidade onde está instalada a Torre Agreste. No caso do BRAMS esta concordância existe para as velocidades de até $6 \mathrm{~m} / \mathrm{s}$. Para as Torres Borborema e Sertão percebe-se boa concordância apenas para velocidades abaixo dos $5 \mathrm{~m} / \mathrm{s}$, a partir daí os modelos apresentam uma tendência em superestimar a velocidade à medida que cresce a altura, sendo o BRAMS ligeiramente menos divergente que o WRF em relação ao perfil observado.

Quanto aos ciclos mensais e diários médios, para a Torre Agreste o WRF acompanha as variações de velocidade média de forma mais concisa. Para as Torres Borborema e Sertão, de forma geral, os ciclos reproduzidos pelo BRAMS tendem a aproximar-se mais aos ciclos observados.

No geral, os dados simulados ajustaram-se bem a distribuição de Weibull. Os coeficientes de correlação encontrados revelam que há forte correlação entre as séries de dados simulados e observado. Diante da interpretação dos erros absoluto e quadrático médio, tem-se que o BRAMS foi melhor para as localidades que estão nas regiões da Borborema e do Sertão, ao passo que o WRF mostrou-se melhor para a área situada no Agreste.

Como sugestão para trabalhos futuros seria interessante realizar novos experimentos com condições iniciais diferentes das utilizadas aqui, além de melhores dados de superfície. Seria interessante também investigar as melhorias obtidas em experimentos realizados com alta resolução, bem como a utilização de modelos de microescala para detectar fenômenos que ocorrem em pequenos intervalos de tempo.

\section{Agradecimentos}

Os autores agradecem a Coordenação de Aperfeiçoamento de Pessoal de Nível Superior (CAPES), pelo suporte financeiro e a Universidade Federal de Campina Grande.

\section{Referências}

ANEEL: Banco de Informações de Geração - BIG: Capacidade de Geração do Estado da Paraíba. 2016. Disponível em
http://www2.aneel.gov.br/aplicacoes/ResumoEstadual/Cap acidadeEstado.cfm? cmbEstados=PB:PARA $\%$ CDBA Acesso 02 set. 2016.

BARBETTA, P.A. Estatística aplicada às Ciências Sociais. $7^{\mathrm{a}}$ ed. Florianópolis: Editora da UFSC, 2010.

BRASIL. Ministério de Minas e Energia/Empresa de Pesquisa Energética - MME/EPE: Plano Decenal de Expansão de Energia 2021. Brasília, 2012. Disponível em http://www. mme.gov.br/mme/galerias/arquivos/noticias/2012/Relatxri o_PDE2021_ConsultaPxblica.pdf. Acesso: 09 jan. 2013.

BRUNI, A.L. Estatística aplicada à gestão empresarial. São Paulo: Atlas, 396 p, 2007.

CAMELO, H.N.; DE MARIA, P.H.S.; CARVALHO, P.C.M.; PEREIRA, T.B. Métodos de Extrapolação de Velocidade do Vento para Regiões Litorâneas do Nordeste Brasileiro. In: XVI Congresso Brasileiro de Meteorologia, Belém, Pará, 13 - 17 de Setembro, 2010. Disponível em http://www.cbmet2010.com/anais/artigos/474_65917.pdf. Acesso em: 4 jan. 2013.

CUNHA, E.B.A.C.; LEAL JUNIOR, J.B.V.; ALMEIDA, G.P. Sensibilidade do modelo RAMS à parametrização de turbulência na simulação de vento em região serrana. In: XV Congresso Brasileiro de Meteorologia, 2008, São Paulo. Anais Eletrônicos. Rio de Janeiro: SBMET, 2008.

DE MARIA, P.H. S. Modelagem numérica em alta resolução para previsão de geração de energia eólica no Ceará. 123f. Dissertação (Mestrado em Ciências Físicas Aplicadas) - Universidade Estadual do Ceará, 2007.

DEVORE, J.L. Probabilidade e estatística para engenharia e ciência. São Paulo: Thomson Pioneira, 706 p., 2006.

DIAS, J.R. Modelo de transformação de energia eólica num fluxo de água com alta pressão para dessalinização por osmose reversa ou/e geração de eletricidade. $221 \mathrm{f}$. Tese (Doutorado em Engenharia Elétrica) - Escola Politécnica da Universidade de São Paulo, 2010.

FERREIRA, A.G.; MELLO, N.G.S. Principais sistemas atmosféricos atuantes sobre a região nordeste do Brasil e a influência dos Oceanos Pacífico e Atlântico no clima da região. Revista Brasileira de Climatologia, v. 1, n. 1, p. 15-28, 2005.

HASTENRATH, S.; HELLER, L. Dynamics of climatic hazards in Northeast Brazil. Quartely Journal Royal Meteorological Society, v. 103, p. 77-92, 1977.

HENNESSEY Jr, J.P. Some aspects of wind power statistics. Journal of Applied Meteorology, v. 16, n. 2, p. 119-128, 1977.

JUSTUS, C.G.; HARGRAVES, W.R.; MIKHAIL, A.; GRABER, D. Methods for estimating wind speed frequency distributions. Journal of Applied Meteorology, v. 17, n. 3, p. 350-353, 1978.

KOUSKY, V.E.; CHU, P.S. Fluctuations in annual rainfall for Northeast Brazil. Journal of the Meteorological Society of Japan, v. 57, p. 457-465, 1978.

LAZIC, L.; PEJANOVIC, G.; ZIVKOVIC, M. Wind forecasts for wind power generation using the Eta model. Renewable Energy, v. 35, p. 1236-1243, 2010.

LIMA, F.J.L. Avaliação do potencial eólico no Estado da Paraíba: um estudo observacional e numérico. 80f. Dissertação (Mestrado em Meteorologia) - Universidade Federal de Campina Grande, 2011. 
LIMA, F.J.L.; CAVALCANTI, E.P.; SOUZA, E.P.; SILVA, E.M. Evaluation of the Wind Power in the State of Paraíba Using the Mesoscale Atmospheric Model Brazilian Developments on the Regional Atmospheric Modelling System. ISRN Renewable Energy, v. 2012, p. 16, 2012. Disponível em http://www.hindawi.com/isrn/re/2012/847356/. Acesso em: 28 dez. 2012.

LOPES, A.M.G. Windstation Version 2.0.6 User's Manual. EasyCFD. Coimbra. 2010.

MANWELL, J.F.; MCGOWAN, J.G.; ROGERS, A.L. Wind energy explained. New York: Wiley, 569 p, 2002.

MARIANO NETO, B. Geografia: Textos, Contextos e Pretextos para o Planejamento Ambiental. $1^{a}$ ed. - Guarabira: Gráfica São Paulo, 2003.

MENEZES, H.E.A. Influência da Zona de Convergência Secundária do Atlântico Sul Sobre a Ocorrência de Precipitação no Leste do Nordeste Brasileiro. 103 p. Tese (Doutorado em Meteorologia) - Universidade Federal de Campina Grande, 2010.

MICHALAKES, J.; DUDHIA, J.; GILL, D.; HENDERSON, T.; KLEMP, J.; SKAMAROCK, W.; WANG,W. The Weather Reseach and Forecast Model: Software Architecture and Performance, in: Proceedings of the $\mathbf{1 1}^{\text {th }}$ ECMWF Workshop on the Use of High Performance Computing In Meteorology, 2004.

PEREIRA, A.C.C. Estudo dos Ventos no Rio Grande do Sul e Simulação para um Ciclone Extratropical usando o Modelo MM5. 161f. Dissertação (Mestrado em Meteorologia) - Universidade Federal de Pelotas, Pelotas, 2008.

PIELKE, R.A.; COTTON, W.R.; WALKO, R.L.; TREMBACK, C.J.; LYONS, W.A.; et al. A comprehensive meteorological modeling system - RAMS. Meteorological and Atmospheric Physical, v. 49, p. 69-91, 1992.

RAMOS, D.N.S.; LYRA, R.F.F.; SILVA JÚNIOR, R.S. Previsão do vento utilizando o modelo atmosférico WRF para o estado de Alagoas. Revista Brasileira de Meteorologia, v. 28, n. 2, p. 163-172, 2013.

REDECIDADEDIGITAL.COM.BR. Disponível em http://redecidadedigital.com.br/mapa_br.php. Acesso em 04 set. 2016.

RODRIGUEZ, J.L. Atlas Escolar da Paraíba. $3^{\text {a }}$ ed., João Pessoa: Editora Grafset, 2002.
ROHATGI, J.S. Wind characteristics: An analysis for the generation of wind power. $1^{a}$ ed. Canyon: Alternative Energy Institute, West Texas A\&M University, 1994.

SANSIGOLO, C.A. Distribuições de Probabilidade de Velocidade e Potência do Vento. Revista Brasileira de Meteorologia, v. 20, n. 2, 2005.

SANTOS, M.; SANTIAGO, G.; GONZÁLEZ, M. Medição de Desempenho na Etapa de Prospecção de Parques Eólicos: O Que Medir? In: Brazil Windpower Conference, Rio de Janeiro-RJ, 2015. Disponível em http://www2.ctee.com.br/brazilwindpower/2015/papers/George_Santiago.pdf. Acesso em: 01 out. 2016.

SAUER, I.L.; QUEIROZ, M.S.; MIRAGAYA, J.C.G.; MASCARENHAS, R.C.; QUINTINO JÚNIOR, A.R. Energias Renováveis: Ações e Perspectivas na Petrobras. Análise e Dados. Salvador, Bahia. v. 16, n. 1, p. 9-22. 2006.

SILVA, C.D.; SERAPHIM, O.J.; TEIXEIRA, N.M. Potencial eólico para bombeamento de água na fazenda Lageado. In: Encontro de Energia no Meio Rural 3, Campinas, 2003. Disponível em http://www.proceedings.scielo.br/scielo.php?pid=MSC0000000022000000200 032\&script=sci_arttext. Acesso em: 03 out. 2016.

SILVA, G.R. Características de Vento da Região Nordeste. 141f. Dissertação (Mestrado em Engenharia Mecância) Universidade Federal de Pernambuco, 2003.

SILVA, N.F.; ROSA, L.P.; ARAÚJO, M.R. The utilization of Wind energy in the Brazilian electric sector's expansion. Renew. Sust. Energ. Rev., v. 9, p. 289-309, 2005.

VALENÇA, D.A.A. Proposição de uma metodologia para a avaliação do aproveitamento da energia eólica em ambiente urbano. 130f. Dissertação (Mestrado em Engenharia Mecânica) - Universidade Federal de Pernambuco, 2010.

WANG, X.; GUO, P.; HUANG, X. A Review of Wind Power Forecasting Models. Energy Procedia, v. 12, p. 770-778, 2011.

WEBER, R.L.; BUCKNER, M.; WEBER, J. Statistical Performance of several mesoscale atmospheric dispersion models. Journal of Applied Meteorology, v. 21, n. 11, p. 16331644, 1982.

This is an Open Access article distributed under the terms of the Creative Commons Attribution Non-Commercial License which permits unrestricted non-commercial use, distribution, and reproduction in any medium provided the original work is properly cited. 